\title{
Learning behaviors, executive functions, and social skills: A meta-analysis on the factors influencing learning development in the transition from kindergarten to elementary school
}

\author{
Henriette Offer-Boljahn' ${ }^{1}$, Dennis Christian Hövel ${ }^{2}$ and Thomas Hennemann ${ }^{3}$ \\ ${ }^{1}$ University of Cologne, Faculty of Human Sciences, Germany (ORCID: 0000-0002-7736-4924) \\ ${ }^{2}$ University of Applied Sciences in Special Needs Education (HfH), Switzerland (ORCID: 0000-0003-0933-2661) \\ ${ }^{3}$ University of Cologne, Faculty of Human Sciences, Germany (ORCID: 0000-0003-4961-8680)
}

\begin{abstract}
The linguistic, mathematical, social-emotional, and cognitive precursor competencies are important predictors of learning success already at kindergarten age. A systematic analysis of the state of research on the actual interrelationships of the focused precursor competencies brings together results of a metaanalysis. The literature search yielded 653 hits, which were reduced to 94 hits after applying exclusion criteria. It was possible to perform 271 correlation tests in 39 pathways. Thus, the sample $(n=141,508$ $[M=1505, S D=3930])$ with an average age of 5.2 years $(S D=0.10$ years $)$ is balanced in gender ratio of $48.5 \%$ male and $48.9 \%$ female (2.6\% not specified). The largest correlation between literacy and mathematical precursor skills is $r=.65$. With a correlation between $r=.17$ and $r=.60$, executive functions significantly influence the development of literacy and mathematical skills and learning behaviors. Learning behaviors are most strongly related to social skills, with $r=.57$. Parental influence turns out to be smaller, with correlations ranging from $r=.19$ to .55 . The effect of individual pathways is also small, and peer group was not included in the search term combination. Successful educational processes in day care centers can be improved with a focus on the promotion of executive functions and learning behaviors.
\end{abstract}

Keywords: Pre-primary education; Executive functions; Learning behaviors; Social-emotional learning; Predictors

Article History: Submitted 4 September 2021; Revised 11 January 2022; Published online 8 February 2022

\section{Introduction}

In order to support learning success at an early age, learning at kindergarten age is increasingly becoming the focus of educational research. Findings of previous research show that negative learning experiences at kindergarten age can inhibit the motivation and effort of prospective school-aged children (Viljaranta et al., 2009). Kindergarten age refers to children between the ages of four and six years, as most OECD countries provide early education services in this age group in

Address of Corresponding Author

Henriette Offer-Boljahn, University of Cologne, Faculty of Human Sciences, Department of Health Education and Rehabilitation, Lehrstuhl für Erziehungshilfe und sozial-emotionale Entwicklungsförderung, Klosterstrasse 79 c, Brieffach 9, 50931 Köln, Germany.

$\triangle$ h.offer-boljahn@uni-koeln.de

How to cite: Offer-Boljahn, H., Hövel, D. C., \& Hennemann, T. (2022). Learning behaviors, executive functions, and social skills: A metaanalysis on the factors influencing learning development in the transition from kindergarten to elementary school. Journal of Pedagogical Research, 6(1), 1-17. https:/ / dx.doi.org/10.33902/JPR.20221175398 
the context of early childcare (OECD, 2021). So-called precursor skills in literacy and early math skills among kindergarten-aged children are discussed in numerous studies as important predictors regarding the children's later literacy and math skills and can therefore counteract negative learning experiences (e.g., Duncan et al., 2007; Hohm et al., 2017; Lonnemann \& Hasselhorn, 2018; Puolakanaho et al., 2008). Other than obvious learning related domains, the OECD Professionals Survey (Bader et al., 2019) has highlighted that social-emotional skills and their promotion are highly valued by parents and professionals in childcare settings. $87 \%$ of the respondents stated that they consider the promotion of cooperation skills to be particularly important, which even exceeds the assessment of the importance of language skills at around $83 \%$ (Bader et al., 2019). Professionals in the eight OECD countries participating in the survey report having particularly frequent conversations with children about their emotions. Thus, the need for early promotion of social-emotional competencies is extremely high, as, for example, positive learning experiences support motivation to engage with learning content (Blewitt, et al., 2018; Viljaranta et al., 2009).

Several other studies also emphasize the importance of basic cognitive skills and welldeveloped working memory in context of preparation for elementary school, (e.g., by relieving the available knowledge in learning and problem solving from working memory capacities, thus creating resources for newly acquired knowledge) and therefore should be considered when discussing early learning at kindergarten age (Faust et al., 2012; Hasselhorn \& Grube, 2008). For practical reasons, it can be a real challenge to incorporate all these developmental areas into an educational design simultaneously and in a quality manner. A multifactorial orientation of early education in day care centers can help to implement high quality pre-elementary education to prepare for a successful transition to elementary school.

\subsection{The Interrelationships of Learning Areas at Kindergarten Age}

Various studies (including Gasteiger-Klicpera et al., 2006; Gold, 2018; Mähler et al., 2017; Reinelt et al., 2019) illustrate that learning domains are mutually dependent regarding school learning success, although the respective cause-effect relationships cannot be fully clarified (Schuchardt \& Kuhn, 2019). For example, Duncan et al. (2007) point out the importance of early school readiness skills, such as prior knowledge, attention, social-emotional skills, and mathematical precursor skills; they note that these precursor skills can have a lasting impact on later learning success with respect to students' numeracy and literacy. Cognitive skills, such as working memory skills, have also been found to be significant precursor skills for learning and school success (Bredel, 2016; Hasselhorn \& Grube, 2008; Marx, 2006; Marx \& Keller, 2010; Schulze \& Kuhl, 2019). Mähler et al. (2017) illustrate the links between cognitive and social-emotional competencies in terms of wellbeing and school success, while Reinelt et al. (2019) depict problematic externalizing behaviors in early infancy or in kindergarten in relation to later poor school performance and reduced success in forming relationships with others. Gasteiger-Klicpera et al. (2006) point to a link between reading and spelling difficulties and behavioral difficulties, which may have a corresponding negative impact on children's academic learning success.

Discussing the importance of the domains of literacy, numerical, cognitive, and socialemotional competences lead to the question how to install high quality education in a daily routine at childcare centers. In this context, Offer-Boljahn et al. (2019) applied the concept of cross-domain support of developmental domains and list combined support programs that were suitable for the preschool year and tested for their effectiveness. It could be mapped that in these combined programs especially educational elements of social-emotional competencies (i.e., emotion knowledge or prosocial behavior) was implemented in all six programs in combination with academic learning content (e.g., language promotion, basic mathematical skills, and thinking strategies). Despite the wide range of evidence on the impact of the discussed early domainspecific competences, there is no current overview of the correlations in pre-primary education. 


\subsection{Aims}

Pre-primary education concerns more than just reading and writing. The results of the studies discussed in the above underline the importance of literacy, numerical as well as socio-emotional and cognitive education to support children in their learning at an early age. Prior knowledge can contribute to the relief of working memory capacities to help successful information processing and the expansion of knowledge. In addition, early linguistic competencies can lead to an understanding of knowledge, and the formation of early social-emotional competencies can contribute to the shaping of relationships and participation. Furthermore, these competencies enable the recall of cognitive functions and thus shape social interaction in a sustainable way. Thus, a systematic analysis on the actual interrelationships of the developmental areas of literacy and mathematical, as well as social-emotional and cognitive competencies in kindergarten-aged children is not yet available. The study examined the following question: How do the developmental domains of literacy, numerical precursor skills, cognitive and socio-emotional competences correlate at the age of four- to six-year-olds? Insights gained from this research could yield important clues for the pedagogical practice of pre-primary education with a cross-domain approach in the context of the transition to elementary school. This article presents the results of a systematic literature search and tries to fill gaps in the research with the help of a meta-analytical approach.

\section{Method}

\subsection{Data Collection}

Studies met inclusion criteria if (1) they included children aged 4 to 6 years as the OECD countries apply pre-primary education at this age and most children can be reached for high-quality educational means in childcare centers at this age; (2) at least two of the four domains of language and mathematical precursor skills, social-emotional skills, and cognitive skills had to be considered in relation to one another; (3) they assessed data from non-selective samples; (4) they used a quantitative design; (4) they were available in German or English; and (5) they were published in peer-reviewed scientific journals between January 2002 and December 2019 and were retrievable. The time period was chosen because around the early 2000's obligatory educational plans for pre-primary education were published by committees in the OECD countries and a corresponding thematization in the literature has been assumed.

To identify relevant studies, a systematic search was conducted using the Academic Search Complete, ERIC, PsychARTICLES, PsychINFO, and PSYNDEX databases. This search involved combining search terms that pertained to the topic area of interest. The combination of terms included four search term groups related to preschool developmental domains (literacy: reading, writing, literacy, linguistic, speech, phonological awareness, and listening; mathematics: mathematics, numerical, numerous, counting, estimates, calculation, and mathematical ability; social-emotional: emotion understanding, social-emotional, prosocial behavior, executive functioning, self-regulation, social skills, externalizing, internalizing, and behavior; and cognition: working memory, concentration, attention, and cognitive development). Two further groups of search terms referred to the type of competencies (predictors: prediction, precursor, forecasting, model, and projection) and the relationship to learning success (learning: academic achievement, comprehension, successful learning, motivation, academic aptitude, and ability). The target group was included in the combination of terms using relevant terms to describe the age group and educational institution (i.e., preschool, kindergarten, school transition, primary/elementary school, school age, school readiness, early childhood education, and preschool age). The process of data selection is illustrated in Figure 1. All information was conducted in accordance with the Preferred Reporting Items for Systematic Reviews and Meta-analyses (PRISMA) reporting guideline (Liberati et al., 2009). The titles and abstracts of the hit set were screened and filtered using the above criteria. The search yielded 653 hits, which were reduced to 572 after duplicates were 
removed by EBSCOhost. After reviewing the titles and abstracts, 359 publications were excluded because they mostly addressed older age groups $(k=79)$ or included differing variables of development $(k=149)$. Another $k=126$ studies included selective samples, e.g. children with ADHD or specific diseases. A total of $k=4$ studies did not refer to a quantitative study design and $\mathrm{k}=1$ study had not been readable due to language. The remaining $k=213$ manuscripts were screened, and an additional $k=119$ studies were excluded for similar reasons: A total of $k=35$ did not meet the age criterion, $k=46$ included differing variables in their data selection, $k=21$ studies revealed selective samples and $k=17$ manuscripts were excluded because of differing criteria regarding the respective study design. The systematic search ultimately identified 94 papers that fit the criteria. The results of the literature search were reviewed by two independent experts to check the study selection and to control the compliance with the inclusion and exclusion criteria. In this way, it was checked that there was no reviewer bias.

Figure 1

Flow chart showing the results of the literature search

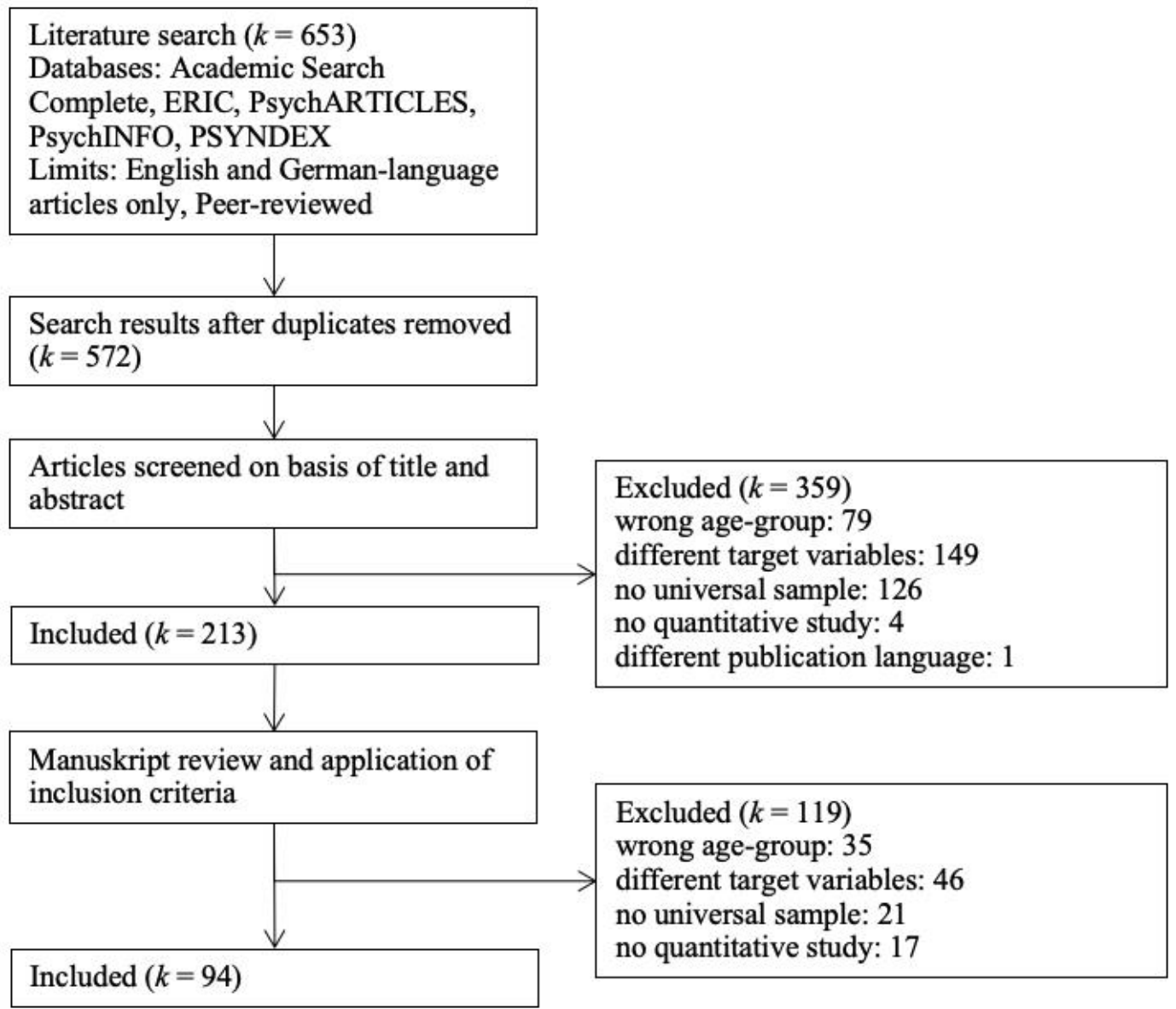

\subsection{Data Analysis}

According to Döring and Bortz (2016), the overall effect and the test of homogeneity of the total of 34 variables were formed. Subsequently, the effect size measure $(\Delta)$ was calculated to obtain a consistent measure of effect size. This measure was then $Z$-transformed $(Z)$, and the variance within studies $(v)$ as well as the weighting factors $(\omega)$ for the studies were calculated. The overall effect size $(\bar{Z})$ was then formed and tested for significance. These steps are necessary to account for unequal effect sizes, study samples, and varying methodological quality across the studies of the hit list by including weighted effect measures in the meta-analysis (Sedlmeier \& Renkewitz, 2013). For the final effect size the respective $95 \%$ confidence interval and the correlation $r$ were 
calculated. With the fixed-effects model, the variables are assumed to be homogeneous, which was tested $(Q)$.

The assignment of the variables concerning the executive functions was done according to the three dimensions of working memory - the visuo-spatial notepad (VS), the phonological loop (PL), and the central executive (EF) - according to Baddeley's (1986) model. This approach was chosen because the identified studies of this work maintain a different terminology in the field of executive functions, and no uniform use of the conceptualization is apparent. Therefore, the assignment was made via the respective description of the measurement levels.

\section{Results}

\subsection{Description of Publications}

The 94 studies in the analysis included 271 tests of correlation. These were summarized in 40 pathways, which are compiled in Table 1. Six additional variables (i.e., parents' numeracy expectations, parent-child numeracy activities, parental education, feelings about school, home learning environment, and classroom quality) were included alongside the core developmental domains and tested for their associations because they showed practical relevance in the studies in the hit list. The data are based on a total sample size of $\mathrm{N}=141,508$ children $(M=1.505$; $S D=3.930$ ) aged 5.2 years $(S D=0.10$ years $)$. With a total distribution of $48.5 \%$ male, $48.9 \%$ female, and $2.6 \%$ no data, the sex ratio is balanced.

Of the studies, 59 \% were conducted in the United States, $6.8 \%$ were from Germany, $5.7 \%$ from Finland, and $4.6 \%$ from the Netherlands. The remaining studies are distributed among Australia, Belgium, Canada, China, Greece, Hong Kong, Israel, Spain, Switzerland, and the United Kingdom. In the period from 2015 to 2019, $52.3 \%$ of the studies were published; another $35.2 \%$ were published between 2010 and 2014, $12.5 \%$ were published between 2005 and 2009. On average, four correlations $(S D=2)$ were tested in each study; the maximum of tested correlations is 14 , and the minimum is one. The most frequent collection method is the test, with $62.7 \%$ of all surveys; $19.2 \%$ of the data were collected by teacher rating and16.6 \% by parents rating, while $1.5 \%$ of the collection method is not specifically named.

Table 1

Results of the fixed-effect model of correlations

\begin{tabular}{|c|c|c|c|c|c|c|}
\hline \multirow{2}{*}{\multicolumn{7}{|c|}{ Working Memory and Learning Behaviors }} \\
\hline & & & & & & \\
\hline Working Memory (WM) - LB & 1 & 157 & $.40^{*}$ & $<0.05^{*}$ & 0.24 & 0.56 \\
\hline Executive functions (WM) - LB & 2 & 18.459 & $.60^{* * *}$ & $12.11^{* * *}$ & 0.49 & 0.71 \\
\hline Visuospatial sketchpad (WM) - LB & 2 & 18.459 & $.30 * * *$ & $3.75^{* * *}$ & 0.14 & 0.46 \\
\hline Phonological loop (WM) - LB & 3 & 34.229 & $.17^{* *}$ & $2.87^{* *}$ & 0.05 & 0.29 \\
\hline Learning behaviors - Social competences & 4 & 14.006 & $.57^{* * *}$ & $8.29 * * *$ & 0.51 & 0.82 \\
\hline Learning behaviors - Aggression & 3 & 16.271 & $.47^{* * *}$ & $6.28^{* * *}$ & 0.35 & 0.66 \\
\hline Working Memory (WM) - Numeracy & 12 & 18.196 & $.34^{* * *}$ & $6.05^{* * *}$ & 0.24 & 0.47 \\
\hline Executive functions (WM) - Numeracy & 21 & 67.243 & $.48^{\star * *}$ & $14.26^{* * *}$ & 0.45 & 0.59 \\
\hline Visuospatial sketchpad (WM) - Numeracy & 27 & 32.142 & $.42^{* * *}$ & $10.58 * * *$ & 0.37 & 0.53 \\
\hline Phonological loop (WM) - Numeracy & 19 & 26.655 & $.23 * * *$ & $4.62 * * *$ & 0.13 & 0.32 \\
\hline Working Memory (WM) - Literacy & 14 & 18.120 & $.27 * * *$ & $4.72 * * *$ & 0.16 & 0.39 \\
\hline Executive functions (WM) - Literacy & 27 & 50.234 & $.38^{\star * *}$ & $10.39 * * *$ & 0.32 & 0.47 \\
\hline Visuospatial sketchpad (WM) - Literacy & 30 & 49.167 & $.23^{* * *}$ & $6.36 * * *$ & 0.16 & 0.31 \\
\hline Phonological loop (WM) - Literacy & 25 & 28.697 & $.28^{* * *}$ & $6.54^{* * *}$ & 0.20 & 0.38 \\
\hline
\end{tabular}


Table 1 continued

\begin{tabular}{|c|c|c|c|c|c|c|}
\hline Variables & $k$ & $n$ & $r$ & $Z$ & \multicolumn{2}{|c|}{$95 \% \mathrm{CI}$} \\
\hline \multicolumn{7}{|l|}{ Parents and Academic Achievement } \\
\hline Parents' numeracy expectations - Numeracy & 2 & 149 & $.55^{* *}$ & $2.5^{* *}$ & 0.13 & 1.00 \\
\hline Parent-child numeracy activities - Numeracy & 2 & 149 & $.44^{*}$ & $1.94 *$ & 0.00 & 0.95 \\
\hline Parental education - Numeracy & 12 & 9.313 & $.39^{* * *}$ & $6.90^{* * *}$ & 0.30 & 0.53 \\
\hline Feelings about school - Numeracy & 1 & 467 & $.34^{*}$ & $<0.05^{*}$ & 0.24 & 0.44 \\
\hline Parents' numeracy expectations - Literacy & 2 & 149 & .34 & 1.46 & 0.00 & 0.83 \\
\hline Parental education - Literacy & 11 & 9.146 & $.32 * * *$ & $5.45^{* * *}$ & 0.21 & 0.45 \\
\hline Feelings about school - Literacy & 1 & 467 & $.32 *$ & $<0.05^{*}$ & 0.23 & 0.41 \\
\hline Home Learning Environment - Literacy & 5 & 5.868 & $.26^{* * *}$ & $3.35^{* * *}$ & 0.11 & 0.42 \\
\hline Parent-child numeracy activities - Literacy & 3 & 270 & .22 & 1.20 & 0.00 & 0.60 \\
\hline Home Learning Environment - Numeracy & 4 & 2.618 & $.19^{*}$ & $1.89 *$ & -0.01 & 0.38 \\
\hline \multicolumn{7}{|l|}{ Literacy and Numeracy } \\
\hline Literacy - Numeracy & 52 & 39.385 & $.65^{* * *}$ & $20.77^{* * *}$ & 0.59 & 0.71 \\
\hline Classroom quality - Literacy & 2 & 1.437 & $.53 * * *$ & $4.25^{* * *}$ & 0.32 & 0.86 \\
\hline Grammatical ability - Numeracy & 3 & 279 & $.49^{* *}$ & $2.84^{* *}$ & 0.17 & 0.91 \\
\hline IQ - Numeracy & 23 & 9.196 & $.44^{* * *}$ & $9.29^{* * *}$ & 0.37 & 0.57 \\
\hline IQ - Literacy & 21 & 7.445 & $.43^{* * *}$ & $8.25^{* * *}$ & 0.34 & 0.56 \\
\hline Grammatical ability - Literacy & 3 & 279 & $.42^{* *}$ & $2.35^{* *}$ & 0.07 & 0.82 \\
\hline \multicolumn{7}{|l|}{ Behavior and Academic Achievement } \\
\hline Hyperactivity/Inattention - Numeracy & 7 & 17.785 & $.37^{* * *}$ & $6.17^{* * *}$ & 0.27 & 0.52 \\
\hline Hyperactivity/Inattention - Literacy & 3 & 13.710 & $.29 * * *$ & $3.54^{* * *}$ & 0.13 & 0.47 \\
\hline Social-emotional skills - Numeracy & 7 & 36.440 & $.28^{* * *}$ & $5.48^{* * *}$ & 0.18 & 0.38 \\
\hline Social-emotional skills - Literacy & 10 & 37.004 & $.25^{\star * *}$ & $5.23^{* * *}$ & 0.16 & 0.35 \\
\hline Self-regulation - Numeracy & 6 & 47.837 & $.23^{* * *}$ & $4.65^{* * *}$ & 0.13 & 0.32 \\
\hline Self-regulation - Literacy & 7 & 47.943 & $.21^{* * *}$ & $4.32^{* * *}$ & 0.11 & 0.30 \\
\hline Externalizing problem behaviors - Numeracy & 4 & 40.644 & .05 & -0.98 & 0.00 & 0.05 \\
\hline Externalizing problem behaviors - Literacy & 6 & 44.238 & .08 & -1.73 & 0.00 & 0.01 \\
\hline Internalizing problem behaviors - Numeracy & 3 & 40.319 & .04 & -0.73 & 0.00 & 0.07 \\
\hline Internalizing problem behaviors - Literacy & 4 & 40.663 & .03 & -0.64 & 0.00 & 0.07 \\
\hline
\end{tabular}

Note. Total sample size: $k=94, N=141,508(M=1.505 ; S D=3.930)$; $\mathrm{k}=$ total number of studies per variable, $\mathrm{n}=$ total number of participants per variable, $\mathrm{LB}=$ learning behaviors; ${ }^{* * *} p<.001,{ }^{* *} p<.01,{ }^{*} p<.05$.

\subsection{Working Memory and Learning Behaviors}

Results are presented with correlation coefficient $r$. This is a measure of strength and direction of a linear relationship of two variables. According to Cohen (1988) it is interpreted as small from 0.1, as moderate from 0.3 and as large from 0.5. A total of eight comparisons were made in the areas of working memory and learning behaviors (Table 1). The learning domains are related with a medium correlation. A single study is represented in the work of Sasser et al. (2015), which forms an overall score for working memory and enters the study with a moderate correlation: $r=.40$, $p<.05,95 \% \mathrm{CI}$ for $r(0.24,0.56)$. When looking at the individual facets of working memory, a more heterogeneous picture of the results emerges. Phonological loop $(r=.17, p<.01,95 \%$ CI for $p$ [0.05, $0.29])$ and visuospatial notepad $(r=.30, p<.001,95 \% \mathrm{CI}$ for $r[0.14,0.46])$ are related with a small to moderate correlation with learning behaviors. At $r=.60, p<.001,95 \%$ CI for $r(0.49,0.71)$, executive functions are related to learning behaviors with a large correlation. The relationship between social skills and learning behaviors was examined by $\mathrm{k}=4$ studies and showed a large relationship overall $(r=.57, p<.001,95 \% \mathrm{CI}$ for $r$ [0.51, 0.82]). Between learning behaviors and aggressive behaviors, $\mathrm{k}=3$ papers identify a moderate relationship $(r=.47, p<.001,95 \% \mathrm{CI}$ for $r$ $[0.35,0.66])$. The three dimensions of working memory (EF, VS, PL) were examined most frequently across the hit list in terms of their associations with both mathematical precursor skills 
$(\mathrm{k}=78)$ and literacy $(\mathrm{k}=95)$. Considered together, all identified correlations fall within the range of moderate correlations. Executive functions achieved the strongest correlations in each of the two skill areas: $r=.48, p<.001,95 \%$ CI for $r(0.45,0.59)$ and $r=.38, p<.001,95 \%$ CI for $r(0.32,0.47)$. The visual-spatial notepad has a moderate correlation with mathematical precursor skills: $r=.42$, $p<.001,95 \%$ CI for $r(0.37,0.53)$. In contrast, the correlation of working memory with literacy is small: $r=.23, p<.001,95 \%$ CI for $r(0.16,0.31)$. The phonological loop has a small correlation with respect to both skill areas: $r=.23, p<.001,95 \%$ CI for $r(0.13,0.32)$ and $r=.28, p<.001,95 \%$ CI for $r(0.20,0.38)$. Compared to the results regarding learning behaviors, the correlations with antecedent competencies in math skills and literacy are lower, with small correlations.

\subsection{Parents and Academic Achievement}

Parental expectation of the child's mathematical skills is largely related to the child's surveyed mathematical skills $(k=2, r=.55, p<.01,95 \%$ CI for $r[0.13,1.00]$, whereas these expectations are not significantly related to literacy skills. Activities between the parent and child, e.g., counting together or playing counting games together in daily life, are moderately related to mathematical antecedent skills $(k=2, r=.44, p<.05,95 \% \mathrm{CI}$ for $r$ [0.00, 0.95]). The relationship to the literacy learning domain is not statistically relevant. Parental education is related to both learning domains of literacy and math prerequisite skills with moderate correlations of $r=.39(k=12, p<.001,95 \%$ CI for $r$ [0.30, 0.53] and $r=.32(k=11, p<.001,95 \%$ CI for $r$ [0.21, 0.45]). The variable of feelings about school is related to mathematical precursor skills with a moderate correlation $(r=.34, k=1$, $p<.05,95 \%$ CI for $r$ [0.24, 0.44]). In relation to literacy, this relationship is slightly smaller, but still interpreted as a moderate correlation $(k=1, r=.32, p<.05,95 \% \mathrm{CI}$ for $r[0.23,0.41])$.

\subsection{Literacy and Numeracy}

The developmental domains of literacy and math antecedent skills were examined with $k=52$ studies and achieved a large correlation: $r=.65, p<.001,95 \% \mathrm{CI}$ for $r(0.59,0.71)$. With $k=2$ papers, the relationship between classroom quality and literacy $(r=.53, p<.001,95 \%$ CI for $r[0.32$, 0.86]) was examined, and a large correlation was found. Regarding grammatical ability and the developmental domains of mathematical precursor skills and literacy, moderate correlations were found in each $k=3, r=.49, p<.01,95 \%$ CI for $r(0.17,0.91)$ and $r=.42, p<.01,95 \%$ CI for $r(0.07$, 0.82). IQ was considered in relation to antecedent competencies in mathematics $(k=23, r=.44$, $p<.001,95 \%$ CI for $r[0.37,0.57])$ and literacy $(k=21, r=.43, p<.001,95 \%$ CI for $r[0.34,0.56])$, depicting a moderate correlation in both cases.

\subsection{Behavior and Academic Achievement}

Regarding the correlation tests, behaviorally relevant variables and the learning domains of mathematical precursor skills and literacy were examined with the largest samples shown here $(n=366,583)$. The correlations found are small to moderate. Hyperactivity and inattention have a small correlation with preschool mathematical precursor skills: $r=.37(k=7, p<.001,95 \%$ CI for $r$ $[0.27,0.52])$. In contrast, language skills have a smaller correlation: $r=.29(k=3, p<.001,95 \% \mathrm{CI}$ for $r[0.13,0.47])$. Social-emotional competencies and the developmental domains of mathematical precursor skills and literacy are related with a small to moderate correlation $(k=7, r=.28, p<.001$, $95 \%$ CI for $r[0.18,0.38]$ and $k=10, r=.25, p<.001,95 \%$ CI for $r[0.16,0.35])$. As part of the executive functions, which were mapped separately in the studies, the relationship between selfregulation and literacy and mathematical antecedent skills is estimated to be small $(k=6, r=.23$, $p<.001,95 \%$ CI for $r[0.13,0.32]$ and $k=7, r=.21, p<.001,95 \%$ CI for $r[0.11,0.30])$. There is no statistically relevant relationship between externalizing and internalizing problem behaviors with respect to the literacy and mathematical precursor skills learning domains. 


\section{Discussion and Conclusion}

The meta-analytic summary of the international study results shows a large correlation between the competence areas of literacy and the mathematical precursor competencies, with $r=.65$. These variables can also be seen in the study results of Duncan et al. (2007) as important predictors for the later learning success of kindergarten-aged children. It is also obvious that the early learning areas are of high importance regarding learning, especially as they represent the central cultural techniques of early school education. Therefore, they are listed and considered in educational curricula and support measures in early childhood, as the assessment of curricula in OECD countries makes clear (OECD, 2021). Here, language learning content is specified and tracked in $98 \%$ of existing education plans. Mathematical precursor competencies are listed in $93 \%$ of the curricula. In these, literacy competencies are rated as especially important by educational professionals (Bader et al., 2019). Mathematical precursor competencies, in contrast, are rated less significant or are less represented in educational curricula (OECD, 2021). However, the results of the present work suggest that these learning areas should be considered equally important and considered in the realization of support services, as they are also highly significant in terms of learning success for school careers (Mähler et al., 2017). Kleemans et al. (2011) see the need for grammatical skills in preparation for linguistic skills as well as early mathematical skills. Similar to the results presented by Offer-Boljahn et al. (2019), two remedial programs could be found that, included both language and mathematical precursor competencies in their curricula. After implementation of the KiDZ program, the competency profiles of the sample expanded in the intervention study (Rossbach et al., 2010). Another important area is working memory. With correlations between $r=.17$ and $r=.60$, executive functions, verbal WM, and visuo-spatial WM are significant factors that influence the development of written language and mathematical competencies as well as learning behaviors. Following the meta-analysis of Peijnenborgh et al. (2015), there is reason to believe that WM can be improved by appropriate school-based training, with small to medium effect sizes ( $\mathrm{g}=0.36$ to 0.63 ). The Tools of the Mind program (Blair \& Raver, 2014), which is also listed in the review paper by Offer-Boljahn et al. (2019), enhances working memory as early as kindergarten age.

The variable concerning learning behaviors is strongly related to social skills, with $r=.57$. Neuenschwander et al. (2012) describe executive functions as abilities that enable learning despite fatigue, distraction, or low motivation in children. Nguyen and Duncan (2018) report a statistically significant relationship between executive functions and learning behavior $(r=.79, p<.001)$. They blame content overlap of the inhibitory control and learning behavior variables for the large association and therefore believe further research using multidimensional survey methods is necessary. Sasser et al. (2015) consider executive functions to be fundamental in establishing learning behaviors. They further state that the dimensions of learning behaviors-such as motivation, cooperation, attention, and persistence-support work in social contact, social participation, and positive play experiences. Thus, social skills and learning behaviors make an important contribution to a child's success in school, i.e., learning to read and facilitate acting on instruction in elementary school mathematics classrooms (Sasser et al., 2015). Accordingly, welldeveloped learning behaviors can strengthen social interaction by providing positive play experiences and establishing and maintaining positive relationships with peers. Similar to the review of Hagarty and Morgan (2020), some evidence for improving the social skills of children and adolescents with learning disabilities is also found for interventions based on social-emotional learning (SEL) theory. In their longitudinal study with a randomized experimental-control group design ( $\mathrm{n}=1,634)$, McCormick et al. (2019) examined the effects of SEL over a five-year period. The authors provide evidence of the significant effect of SEL on the need for special education needs assignments (i.e., students who participated in SEL showed a lower rate of special education needs). SEL can therefore be seen as an important field of action in instructional and support planning for learning difficulties. The present results do not point to a direct connection between internalizing or externalizing behavior and literacy or mathematical precursor competencies. It can 
therefore be assumed that problems do not initially lead to deficient development, but deficient developmental trajectories can lead to problems. Gasteiger-Klicpera et al. (2006) come to a similar conclusion in the context of behavioral problems and reading alongside with spelling difficulties. Morgan et al. (2018) state that cognitive flexibility, as part of executive functions, has a particularly strong effect. They consider it to be responsible for the regulation of undesirable behaviors in group contexts, as well as inattention. Nevertheless, cognitive flexibility can be useful for blocking out irrelevant information and following instructions, thus facilitating learning in the domains of mathematics and literacy. Miller-Cotto and Byrnes (2019) also suggest that working memory performance and domain-specific skills reinforce each other. Higher performance in the math or literacy skill domains leads to higher working memory performance, which in turn enables higher cognitive processing of new content in the domains. Simultaneously, learning behaviors and aggressive behaviors were collected in the analysis and showed a moderate correlation. Based on parental perceptions of stress, it negatively affects children's learning behaviors and thus leads to negative or undesirable behaviors in a group context, according to Smith-Adcock et al. (2019), which Sasser et al. (2015) also found. In their study, Hassinger-Das et al. (2014) evaluated the relationship of Hyperactivity and inattention in correlation to mathematical and linguistic precursor skills finding out, that low attention may lead to learning delays in early school age. It is evident that maladaptive behavior is often undesired in learning contexts and interferes with learning, whether through the lack of attentiveness or through increased potentially negative awareness by teachers.

Segers et al. (2015) state that the relationship with the child's competency profile is not an outlook on learning development. Nevertheless, the relationship is significant since it is important with respect to the home environment, as positive influences on learning development may be at work here (Ferretti \& Bub, 2017). Parents' learning activities with their children have a small to moderate relationship with their children's ability profiles. With correlations ranging from $r=.19$ to .55 , the home environment, parental expectations of the child, parental educational level, and active practice and operation with numbers between parent and child are low in their influence on the child's kindergarten-aged ability profile. These results highlight the significance of the educational mission of the pedagogical care facility with its resource of pedagogical specialists. With $r=.53$, they can already positively support learning with the help of good classroom management. According to the results of Wustmann Seiler et al. (2017), good spatial and material equipment of the childcare facility and a high quality of interaction can also have a positive effect on children's behavior and dampen any family risk conditions. In terms of support opportunities, the childcare facility therefore offers a viable setting, particularly regarding the promotion of executive functions and learning behavior as well as social skills, which the home environment is less able to provide in this way.

\section{Limitations and Implications}

The individual correlation checks shown here are only thinly represented, which is due to the small number of studies found and to the widely varying sample sizes. In the composition of the search term combination, children, educational professionals, and parents were included. However, the term section on peer group behavior is missing, which may represent another component in the development of competencies, especially regarding SEL.

Fortunately, the competency profiles in the included studies regarding the learning domains of literacy and mathematics precursor competencies could be established using proximal elicitation methods. To further extend the competencies of school learning, school performance could have been another dimension of children's competencies and learning success. However, these were not included in the included studies, which may be due to the age of the children. Performance assessments in the form of grades have not yet been introduced internationally in the age group.

Regarding the terminology, in some cases, strongly different conceptualizations appear in the international comparison. For example, working memory as part of the executive functions has not 
always been clearly identified as such internationally. This is due to the different references to the conceptualizations. The use of the conceptualizations alone does not represent an identical interpretation of them and must be thoroughly examined to avoid ambiguities and confusions. Here, a fundamental clarification is needed against the background that internationally transferable terms and concepts cannot be confused with a country-specific reference model. Thus, the variable of self-regulation is also listed as an individual one in the present results, although it is counted among the executive functions. Therefore, this variable was listed under the behavioral contextual tests.

For the area of early language development, the term literacy was chosen. The individual facets of this term must be traced in the studies in the hit list. A higher operationalization of this learning area meant a disproportionate reduction in the number of cases, which would not have been conducive to the research question of this paper.

Do parents matter? Are they the ones who make the difference in the child's learning success? The results of the meta-analysis have shown that executive functions have an important influence on the learning behavior of children of kindergarten age and can also support the formation of social skills. This finding is highly relevant for practical work in pre-elementary education, as this content, coupled with language and mathematical educational goals, should be specifically included, and focused on in educational programs. Therefore, the results emphasize the importance of the day care center as an educational institution. Competencies of executive functions should be disseminated by trained professionals, as the individual home environment cannot offer this kind of support.

\section{References}

Note. References marked with an asterisk indicate studies included in the meta-analysis.

*Ahmed, S. F., Tang, S., Waters, N. E., \& Davis-Kean, P. (2018). Executive function and academic achievement: Longitudinal relations from early childhood to adolescence. Journal of Educational Psychology, 111(3), 446-458. https://doi.org/10.1037/edu0000296

*Alloway, T. P., \& Alloway, R. G. (2010). Investigating the predictive roles of working memory and IQ in academic attainment. Journal of Experimental Child Psychology, 106(1), 20-29. https://doi.org/10.1016/j.jecp.2009.11.003

*Alloway, T. P., Gathercole, S. E., Adams, A.-M., Willies, C., Eaglen, R., \& Lamont, E. (2005). Working memory and phonological awareness as predictors of progress towards early learning goals at school entry. British Journal of Developmental Psychology, 23(3), 417-426. https://doi.org/10.1348/026151005X26804

*Anders, Y., Rossbach, H.-G., Weintert, S., Ebert, S., Kuger, S., Lehrl, S., \& Maurice, J. (2012). Home and preschool learning environments and their relations to the development of early numeracy skills. Early Childhood Research Quarterly, 27(2), 231-244. https://doi.org/10.1016/j.ecresq.2011.08.003

*Aragón, E., Navarro, J., Aguilar, M., Cerda, G., \& García-Sedeño, M. (2016). Predictive model for early math skills based on structural equations. Scandinavian Journal of Psychology, 57(6), 489-494. https://doi.org/10.1111/sjop.12317

*Arnold, D. H., Kupersmidt, J. B., Voegler-Lee, M. E., \& Marshall, N. A. (2012). The association between preschool children's social functioning and their emergent academic skills. Early Childhood Research Quarterly, 27(3), 376-386. https://doi.org/10.1016/j.ecresq.2011.12.009

*Austin, A. M., \& Blevins-Knabe, B. (2012). Early mathematics and phonological awareness in two child care settings. Early Child Development and Care, 183(9), 1-18. https:/ / doi.org/10.1080/03004430.2012.716832

Baddeley, A. (1986). Working memory. Clarendon Press.

Bader, S., Bloem, S., Riedel, B., Seybel, C., \& Turani, D. (Eds.). (2019). Kita-Praxis im internationalen Vergleich. Ergebnisse der OECD-Fachkräftebefragung 2018 [Daycare Practices in International Comparison. Results of the OECD Teacher Survey 2018]. https://www.dji.de/fileadmin/user_upload/bibs2019/28314_KitaPraxis_im_internationalen_Vergleich.pdf 
Blair, C., \& Raver, C. C. (2014). Closing the achievement gap through modification of neurocognitive and neuroendocrine function: Results from a cluster randomized controlled trial of an innovative approach to the education of children in kindergarten. PLoS ONE, 9(11), 1-13. https://doi.org/10.1371/journal.pone.0112393

Blewitt, C., Fuller-Tyszkiewicz, M., Nolan, A., Bergmeier, H., Vicary, D., Huang, T., McCabe, P., McKay, T., \& Skouteris, H. (2018). Social and emotional learning associated with universal curriculum-based interventions in early childhood education and care centers. A systematic review and meta-analysis. JAMA Network Open, 1, 1-19. https://doi.org/10.1001/jamanetworkopen.2018.5727

Bredel, U. (2016). Schriftspracherwerb. In U. Domahs, \& B. Rimus (Eds.), Handbuch Laut, Gebärde, Buchstabe [Handbook Sound, Gesture, Letter] (pp. 436-454). de Gruyter.

*Bull, R., Espy, K. A., \& Wiebe, S. A. (2008). Short-term memory, working memory, and executive functioning in preschoolers: Longitudinal predictors of mathematical achievement at age 7 years. Developmental Neuropsychology, 33(3), 205-228. https://doi.org/10.1080/87565640801982312

*Bull, R., Espy, K. A., Wiebe, S. A., Sheffield, T. D., \& Nelson, J. M. (2011). Using confirmatory factor analysis to understand executive control in preschool children: Sources of variation in emergent mathematic achievement. Developmental Science, 14(4), 679-692. https://doi.org/10.1111/j.1467-7687.2010.01012.x

*Bulotsky-Shearer, R. J., Fernandez, V., Dominguez, X., \& Rouse, H. L. (2011). Behavior problems in learning activities and social interactions in head start classrooms and early reading, mathematics, and approaches to learning. School Psychology Review, 40(1), 39-56. https:// doi.org/10.1080/02796015.2011.12087727

*Byrnes, J. P., Wang, A., \& Miller-Cotto, D. (2019). Children as mediators of their own cognitive development in kindergarten. Cognitive Development, 50, 80-97. https://doi.org/10.1016/j.cogdev.2019.03.003

${ }^{*}$ Chrysochoou, E., \& Bablekou, Z. (2011). Phonological loop and central executive contributions to oral comprehension skills of 5.5 to 9.5 years old children. Applied Cognitive Psychology, 25(4), 576-583. https://doi.org/10.1002/acp.1723

${ }^{*}$ Cirino, P. T. (2011). The interrelationships of mathematical precursors in kindergarten. Journal of Experimental Child Psychology, 108(4), 713-733. https://doi.org/10.1016/j.jecp.2010.11.004

${ }^{*}$ Clark, C. A., Pritchard, V. E., \& Woodward, L. J. (2010). Preschool executive functioning abilities predict early mathematics achievement. Developmental Psychology, 46(5), 1176-1191. https://doi.org/10.1037/a0019672

Cohen, J. (1988). Statistical power analysis for the behavioral sciences (2nd ed.). Lawrence Erlbaum Associates.

Döring, N., \& Bortz, J. (2016). Forschungsmethoden und Evaluation in den Sozial- und Humanwissenschaften [Research Methods and Evaluation in Social and Human Sciences] (5th ed.). Springer. https://doi.org/10.1007/978-3-642-41089-5

*Davidse, N. J., De Jong, M. T., \& Bus, A. G. (2014). Explaining common variance shared by early numeracy and literacy. Reading and Writing, 27, 631-648. https://doi.org/10.1007/s11145-013-9465-0

Duncan, G. J., Dowsett, C. J., Claessens, A., Magnuson, K., Huston, A. C., Klebanov, P., Pagani, L. S., Feinstein, L., Engel, M., Brooks-Gunn, J., Sexton, H., Duckworth, K., \& Japel, C. (2007). School readiness and later achievement. Developmental Psychology, 43(6), 1428-1446. https://doi.org/10.1037/00121649.43.6.1428

*Elliott, L. (2019). Profiles of academic, cognitive, and behavioral development from kindergarten to third grade. Learning and Individual Differences, 70, 109-120. https:/ / doi.org/10.1016/j.lindif.2019.01.010

Faust, G., Kratzmann, J., \& Wehner, F. (2012). School Entry - a Risk for Schoolbeginners? Zeitschrift für Pädagogische Psychologie, 26(3), 197-212. https:// doi.org/10.1024/1010-0652/a000069

*Ferretti, L., \& Bub, K. L. (2017). Family routines and school readiness during the transition to kindergarten. Early Education and Development, 28(1), 59-77. https://doi.org/10.1080/10409289.2016.1195671

*Forget-Dubois, N., Lemelin, J.-P., Boivin, M., Dionne, G., Séguin, J. R., Vitaro, F., \& Tremblay, R. E. (2007). Predicting early school achievement with the EDI: A longitudinal population-based study. Early Education and Development, 18(3), 405-426. https://doi.org/10.1080/10409280701610796

*Foster, M. E., Anthony, J. L., Clements, D. H., \& Sarama, J. H. (2015). Processes in the development of mathematics in kindergarten children from Title 1 schools. Journal of Experimental Child Psychology, 140, 56-73. https:// doi.org/10.1016/j.jecp.2015.07.004

*Friedman, S. L., Scholnick, E. K., Bender, R. H., Vandergrift, N., Spieker, S., Hirsh Pasek, K., Keating, D. P., \& Park, Y. (2014). Planning in middle childhood: Early predictors and later outcomes. Child Development, 85(4), 1446-1460. https://doi.org/10.1111/cdev.12221 
*Fuchs, L. S., Geary, D. C., Compton, D. L., Fuchs, D., Hamlett, C. L., \& Bryant, J. D. (2010). The contributions of numerosity and domain-general abilities to school readiness. Child Development, 81(5), 1520-1533. https://doi.org/10.1111/j.1467-8624.2010.01489.x

*Fuhs, M. W. (2011). Verbal ability and executive functioning development in preschoolers at Head Start. Developmental Psychology, 47(2), 404-416. https://doi.org/10.1037/a0021065

*Fuhs, M. W., Farran, D. C., \& Nesbitt, K. T. (2015). Prekindergarten children's executive functioning skills and achievement gains: The utility of direct assessments and teacher ratings. Journal of Educational Psychology, 107(1), 207-221. https://doi.org/10.1037/a0037366

*Fuhs, M. W., Nesbitt, K. T., Farran, D. C., \& Dong, N. (2014). Longitudinal associations between executive functioning and academic skills across content areas. Developmental Psychology, 50(1), 1698-1709. https://doi.org/10.1037/a0036633

Gasteiger-Klicpera, B., Klicpera, C., \& Schabmann, A. (2006). Relationship between reading, spelling and behavior disorders: A longitudinal study from kindergarten to the fourth grade of elementary school. Kindheit und Entwicklung, 15(1), 55-67. https://doi.org/10.1026/0942-5403.15.1.55

${ }^{*}$ Geary, D. C., \& vanMarle, K. (2016). Young children's core symbolic and nonsymbolic quantitative knowledge in the prediction of later mathematics achievement. Developmental Psychology, 52(12), 2130 2144. https://doi.org/10.1037/dev0000214

*Georgiou, G. K., Tziraki, N., Manolitsis, G., \& Fella, A. (2013). Is rapid automatized naming related to reading and mathematics for the same reason(s)? A follow-up study from kindergarten to Grade 1. Journal of Experimental Child Psychology, 115(3), 481-496. https:/ / doi.org/10.1016/j.jecp.2013.01.004

*Georgiou, G. K., Wei, W., Inoue, T., Das, J. P., \& Deng, C. (2019). Cultural influences on the relation between executive functions and academic achievement. Reading and Writing, 33, 991-1013. https://doi.org/10.1007/s11145-019-09961-8

Gold, A. (2018). Lernschwierigkeiten. Ursachen, Diagnostik, Intervention [Learning Disorders. Causes, Diagnostics, Interventions] (2nd ed.). Stuttgart: Kohlhammer.

*Graziano, P. A., Reavis, R. D., Keane, S. P., \& Calkins, S. D. (2007). The role of emotion regulation and children's early academic success. Journal of School Psychology, 45(1), 3-19. https://doi.org/10.1016/j.jsp.2006.09.002

Hagarty, I., \& Morgan, G. (2020). Social-emotional learning for children with learning disabilities: A systematic review. Educational Psychology in Practice, 36(2), 208-222. https://doi.org/10.1080/02667363.2020.1742096

Hasselhorn, M., \& Grube, D. (2008). Individual Preconditions and Developmental Constraints of Children's Learning during the Preschool and Early School Years. Empirische Pädagogik, 22, 113-126.

*Hassinger-Das, B., Jordan, N. C., Glutting, J., Irwin, C., \& Dyson, N. (2014). Domain general mediators of the relation between kindergarten number sense and first-grade mathematics achievement. Journal of Experimental Child Psychology, 118, 78-92. https:// doi.org/10.1016/j.jecp.2013.09.008

${ }^{*}$ Hirsch, S., Lambert, K., Coppens, K., \& Moeller, K. (2018). Basic numerical competences in large-scale assessment data: Structure and long-term relevance. Journal of Experimental Child Psychology, 167, 32-48. https://doi.org/10.1016/j.jecp.2017.09.015

Hohm, E., Laucht, M., Zohsel, K., Schmidt, M., Brandeis, G., \& Banaschweski, T. (2017). Resilience and resources during development: From early childhood to adulthood. Kindheit und Entwicklung, 26(4), 230239. https://doi.org/10.1026/0942-5403/a000236

*Hornburg, C. B., Schmitt, S. A., \& Purpura, D. J. (2018). Relations between preschoolers' mathematical language understanding and specific numeracy skills. Journal of Experimental Child Psychology, 176, 84100. https:// doi.org/10.1016/j.jecp.2018.07.005

*Hughes, J., \& Kwok, O.-M. (2007). Influence of student-teacher and parent-teacher relationships on lower achieving readers' engagement and achievement in the primary grades. Journal of Educational Psychology, 99(1), 39-51. https://doi.org/10.1037/0022-0663.99.1.39

*Hughes, J., Luo, W., Kwok, O.-M., \& Loyd, L. K. (2008). Teacher-student support, effortful engagement, and achievement: A 3-year longitudinal study. Journal of Educational Psychology, 100(1), 1-14. https:// doi.org/10.1037/0022-0663.100.1.1

*Isbell, E., Calkins, S. D., Cole, V. T., Swingler, M. M., \& Leerkes, E. M. (2019). Longitudinal associations between conflict monitoring and emergent academic skills: An event-related potentials study. Developmental Psychobiology, 61(4), 495-512. https://doi.org/10.1002/dev.21809 
*Kleemans, T., Peeters, M., Segers, E., \& Verhoeven, L. (2012). Child and home predictors of early numeracy skills in kindergarten. Early Childhood Research Quarterly, 27(3), 471-477. https://doi.org/10.1016/j.ecresq.2011.12.004

*Kleemans, T., Segers, E., \& Verhoeven, L. (2011). Cognitive and linguistic precursors to numeracy in kindergarten: Evidence from first and second language learners. Learning and Individual Differences, 21(5), 555-561. https://doi.org/10.1016/j.lindif.2011.07.008

*Koponen, T., Aunola, K., Ahonen, T., \& Nurmi, J.-E. (2007). Cognitive predictors of single-digit and procedural calculation skills and their covariation with reading skill. Journal of Experimental Child Psychology, 97(3), 220-241. https:// doi.org/10.1016/j.jecp.2007.03.001

*Koponen, T., Salmi, P., Torppa, M., Eklund, K., Aro, T., Aro, M., Poikkeus, A.-M., Lerkkanen, M.-K., \& Nurmi, J.-E. (2016). Counting and rapid naming predict the fluency of arithmetic and reading skills. Contemporary Educational Psychology, 44-45, 83-94. https:// doi.org/10.1016/j.cedpsych.2016.02.004

${ }^{*}$ Krajewski, K., Schneider, W., \& Nieding, G. (2008). Early Training of Quantity - Number Competencies in Preschool. Psychologie in Erziehung und Unterricht, 55, 100-113.

*Kyttälä, M., Aunio, P., Lepola, J., \& Hautamäki, J. (2013). The role of the working memory and language skills in the prediction of word problem solving in 4- to 7-year-old children. Educational Psychology, 34(6), 674-696. https://doi.org/10.1080/01443410.2013.814192

*LeFevre, J.-A., Fast, L., Skwarchuk, S.-L., Smith-Chant, B., Bisanz, J., Kamawar, D., \& Penner-Wilger, M. (2010). Pathways to mathematics: Longitudinal predictors of performance. Child Development, 81(6), $1753-$ 1767. https://doi.org/10.1111/j.1467-8624.2010.01508.x

*Lepola, J., Niemi, P., Kuikka, M., \& Hannula, M. M. (2005). Cognitive-linguistic skills and motivation as longitudinal predictors of reading and arithmetic achievement: A follow-up study from kindergarten to grade 2. International Journal of Educational Research, 43(4-5), 250-271. https://doi.org/10.1016/j.ijer.2006.06.005

${ }^{*} \mathrm{Li}$, Y., Xu, L., Liu, L., Lv, Y., Wang, Y., \& Huntsinger, C. S. (2016). Can preschool socioeconomic composition moderate relationships between family environment and Chinese children's early academic and social outcomes? Children and Youth Services Review, 60, 1-10. https://doi.org/10.1016/j.childyouth.2015.11.009

Liberati, A., Atman, D., Tetzlaff, J., Mulrow, C., Gøtzsche, P., Ioannidis, J., Clarke, M., Devereaux, P., Kleijnen, J., \& Moher, D. (2009). The PRISMA statement for reporting systematic reviews and metaanalyses of studies that evaluate health care interventions: Explanation and elaboration. PLOS Medicine, 6, 1-28. https://doi.org/10.1371/journal.pmed.1000100

${ }^{*}$ Lockl, K., Ebert, S., \& Weinert, S. (2017). Predicting school achievement from early theory of mind: Differential effects on achievement tests and teacher ratings. Learning and Individual Differences, 53, 93-102. https://doi.org/10.1016/j.lindif.2016.11.007

*Lombardi, C. M., Casey, B. M., Thomson, D., \& Nguyen, H. N. (2017). Maternal support of young children's planning and spatial concept learning as predictors of later math (and reading) achievement. Early Childhood Research Quarterly, 41, 114-125. https:// doi.org/10.1016/j.ecresq.2017.07.004

Lonnemann, J., \& Hasselhorn, M. (2018). Early mathematics education: Current research trends and perspectives. Frühe Bildung, 7(3), 129-134. https://doi.org/10.1026/2191-9186/a000379

Mähler, C., Petermann, U., \& Greve, W. (2017). Social-emotional and cognitive skills as regulation competencies. Kindheit und Entwicklung, 26(1), 1-6. https://doi.org/10.1026/0942-5403/a000210

*Martin, R. B., Cirino, P. T., Sharp, C., \& Barnes, M. (2014). Number and counting skills in kindergarten as predictors of grade 1 mathematical skills. Learning and Individual Differences, 34, 12-23. https://doi.org/10.1016/j.lindif.2014.05.006

Marx, E. (2006). Does a child's language system benefit from other domains of cognitive development? A study of the relationship between language acquisition and inductive reasoning. Zeitschrift für Entwicklungspsychologie und Pädagogische Psychologie, 38(3), 139-145. https://doi.org/10.1026/00498637.38.3.139

Marx, E., \& Keller, K. (2010). Effects of an Inductive Reasoning Training on the Development of Language and Intelligence in Preschoolers and First Graders from Socially Disadvantaged Districts. Zeitschrift für Pädagogische Psychologie, 24(2), 139-146. https://doi.org/10.1024/1010-0652/a000011

*McClelland, M. M., Cameron, C. E., Connor, C. M., Farris, C. L., Jewkes, A. M., \& Morrisson, F. J. (2007). Links between behavioral regulation and preschoolers' literacy, vocabulary, and math skills. Developmental Psychology, 43(4), 947-959. https:// doi.org/10.1037/0012-1649.43.4.947 
*McClelland, M. M., Cameron, C. E., Duncan, R., Bowles, P. P., Acock, A. C., Miao, A., \& Pratt, M. E. (2014). Predictors of early growth in academic achievement: The head-toes-knees-shoulders task. Frontiers in Psychology, 5, 1-14. https://doi.org/10.3389/fpsyg.2014.00599

${ }^{*}$ McCormick, M. P., O'Connor, E. E., \& Barnes, S. P. (2016). Mother-child attachment styles and math and reading skills in middle childhood: The mediating role of children's exploration and engagement. Early Childhood Research Quarterly, 36, 295-306. https:// doi.org/10.1016/j.ecresq.2016.01.011

McCormick, M. P., Neuhaus, R., Horn, E. P., O'Connor, E. E., White, H. I., Harding, S., Cappella, E., \& McClowry, S. (2019). Long-term effects of social-emotional learning on receipt of special education and grade retention: Evidence from a randomized trial of INSIGHTS. AERA Open, 5(3), 1-21. https:/ / doi.org/10.1177/2332858419867290

*McLear, C., Trentacosta, C. J., \& Smith-Darden, J. (2016). Child self-regulation, parental secure base scripts, and at-risk kindergartners' academic achievement. Early Education and Development, 27(4), 440-456. https://doi.org/10.1080/10409289.2016.1091972

*Merz, E., Zucker, T. A., Landry, S. H., Williams, J. M., Assel, M., Taylor, H., Lonigan, C., Phillips, B. M., Clancy-Menchetti, J., Barnes, M. A., Eisenberg, N., \& de Villiers, J. (2015). Parenting predictors of cognitive skills and emotion knowledge in socioeconomically disadvantaged preschoolers. Journal of Experimental Child Psychology, 132, 14-31. https:// doi.org/10.1016/j.jecp.2014.11.010

*Miller-Cotto, D., \& Byrnes, J. P. (2020). What's the best way to characterize the relationship between working memory and achievement? An initial examination of competing theories. Journal of Educational Psychology, 112(5), 1074-1084. https://doi.org/10.1037/edu0000395

*Moll, K., Snowling, M. J., Göbel, S. M., \& Hulme, C. (2015). Early language and executive skills predict variations in number and arithmetic skills in children at family-risk of dyslexia and typically developing controls. Learning and Instruction, 38, 53-62. https:// doi.org/10.1016/j.learninstruc.2015.03.004

*Morgan, P. L., Farkas, G., Hillemeier, M., Pun, W. H., \& Maczuga, S. (2019). Kindergarten children's executive functions predict their second-grade academic achievement and behavior. Child Development, 90(5), 1802-1816. https:// doi.org/10.1111/cdev.13095

${ }^{*}$ Mou, Y., Bertletti, I., \& Hyde, D. C. (2018). What counts in preschool number knowledge? A Bayes factor analytic approach toward theoretical model development. Journal of Experimental Child Psychology, 166, 116-133. https:// doi.org/10.1016/j.jecp.2017.07.016

*Nanu, C., McMullen, J., Munck, P., \& Hannula-Sormunen, M. H. (2018). Spontaneous focusing on numerosity in preschool as a predictor of mathematical skills and knowledge in the fifth grade. Journal of Experimental Child Psychology, 169, 42-58. https://doi.org/10.1016/j.jecp.2017.12.011

*Neuenschwander, R., Röthlisberger, M., Cimeli, P., \& Roebers, C. (2012). How do different aspects of selfregulation predict successful adaptation to school? Journal of Experimental Child Psychology, 113(3), 353371. https://doi.org/10.1016/j.jecp.2012.07.004

*Nevo, E., \& Breznitz, Z. (2011). Assessment of working memory components at 6 years of age as predictors of reading achievements a year later. Journal of Experimental Child Psychology, 109(1), 73-90. https://doi.org/10.1016/j.jecp.2010.09.010

*Nguyen, T., \& Duncan, G. J. (2019). Kindergarten components of executive function and third grade achievement: A national study. Early Childhood Research Quarterly, 46, 49-61. https://doi.org/10.1016/j.ecresq.2018.05.006

*Nguyen, T., Duncan, R. J., \& Bailey, D. (2019). Theoretical and methodological implications of associations between executive function and mathematics in early childhood. Contemporary Educational Psychology, 58, 376-287. https:// doi.org/10.1016/j.cedpsych.2019.04.002

*Niklas, F., \& Schneider, W. (2014). Casting the die before the die is cast: the importance of the home numeracy environment for preschool children. European Journal of Psychology of Education, 29, 327-345. https:/ / doi.org/10.1007/s10212-013-0201-6

*Niklas, F., \& Schneider, W. (2017). Home learning environment and development of child competencies from kindergarten until the end of elementary school. Contemporary Educational Psychology, 49, 263-274. https://doi.org/10.1016/j.cedpsych.2017.03.006

*Niklas, F., \& Tayler, C. (2018). Room quality and composition matters: Children's verbal and numeracy abilities in Australian early childhood settings. Learning and Instruction, 54, 114-124. https:// doi.org/10.1016/j.learninstruc.2017.08.006

*Noël, M.-P. (2009). Counting on working memory when learning to count and to add: A preschool study. Developmental Psychology, 45(6), 1630-1643. https://doi.org/10.1037/a0016224 
OECD. (2021). Starting Strong IV. Supporting Meaningful Interactions in Early Childhood Education and Care (Vol. Starting Strong). Paris: OECD Publishing. https://doi.org/10.1787/f47a06ae-en

Offer-Boljahn, H., Hövel, D., \& Hennemann, T. (2019). Multicomponent interventions in early child education: A systematic review. Psychoeducational Assessment, Intervention and Rehabilitation, 1(1), 31-44. https://doi.org/10.30436/PAIR19-01

*Passolunghi, M. C., Lanfranchi, S., Altoè, G., \& Sollazzo, N. (2015). Early numerical abilities and cognitive skills in kindergarten children. Journal of Experimental Child Psychology, 135, 25-42. https://doi.org/10.1016/j.jecp.2015.02.001

*Passolunghi, M. C., Vercelloni, B., \& Schadee, H. (2007). The precursors of mathematics learning: Working memory, phonological ability and numerical competence. Cognitive Development, 22(2), 165-184. https://doi.org/10.1016/j.cogdev.2006.09.001

*Paul, J. M., Gray, S. A., Butterworth, B. L., \& Reeve, R. A. (2019). Reading and math tests differentially predict number transcoding and number fact speed longitudinally: A random intercept cross-lagged panel approach. Journal of Educational Psychology, 111(2), 299-313. https://doi.org/10.1037/edu0000287

Peijnenborgh, J., Hurks, P., Aldenkamp, A., Vles, J., \& Hendriksen, J. (2015). Efficacy of working memory training in children and adolescents with learning disabilities: A review study and meta-analysis. Neuropsychological Rehabilitation, 26(5-6), 645-672. https://doi.org/10.1080/09602011.2015.1026356

*Perry, K. E., Donohue, K. M., \& Weinstein, R. S. (2007). Teaching practices and the promotion of achievement and adjustment in first grade. Journal of School Psychology, 45(3), 269-292. https://doi.org/10.1016/j.jsp.2007.02.005

*Preßler, A.-L., Könen, T., Hasselhorn, M., \& Krajewski, K. (2014). Cognitive preconditions of early reading and spelling: a latent-variable approach with longitudinal data. Reading and Writing, 27, 383-406. https:// doi.org/10.1007/s11145-013-9449-0

*Puccioni, J., Baker, E. R., \& Froiland, J. M. (2019). Academic socialization and the transition to kindergarten: Parental beliefs about school readiness and involvement. Infant and Child Development, 28(6), 1-25. https://doi.org/10.1002/icd.2154

Puolakanaho, A., Ahonen, T., Aro, M., Eklund, K., Leppänen, P., Poikkeus, A.-M., Tolvanen, A., Torppa, M., \& Lyytinen, H. (2008). Developmental links of very early phonological and language skills to second grade reading outcomes. Strong to accuracy but only minor to fluency. Journal of Learning Disabilities, 41(4), 353-370. https:// doi.org/10.1177/0022219407311747

*Purpura, D. J., \& Logan, J. A. (2015). The nonlinear relations of the approximate number system and mathematical language to early mathematics development. Developmental Psychology, 51(12), 1717-1724. https:// doi.org/10.1037/dev0000055

*Purpura, D. J., \& Simms, V. (2018). Approximate Number System development in preschool: What factors predict change? Cognitive Development, 45, 31-39. https://doi.org/10.1016/j.cogdev.2017.11.001

*Purpura, D. J., Logan, J. A., Hassinger-Das, B., \& Napoli, A. R. (2017). Why do early mathematics skills predict later reading? The role of mathematical language. Developmental Psychology, 53(9), 1633-1642. https://doi.org/10.1037/dev0000375

*Rasmussen, C., \& Bisanz, J. (2005). Representation and working memory in early arithmetic. Journal of Experimental Child Psychology, 91(2), 137-157. https://doi.org/10.1016/j.jecp.2005.01.004

Reinelt, T., Samdan, G., Kiel, N., \& Petermann, F. (2019). Predicting Externalizing Behavior Problems in Early Childhood: Evidence From Longitudinal Studies. Kindheit und Entwicklung, 28(1), 19-32. https://doi.org/10.1026/0942-5403/a000268

Rossbach, H.-G., Sechtig, J., \& Freund, U. (2010). Empirische Evaluation des Modellversuchs "Kindergarten der Zukunft - KiDZ". Ergebnisse der Kindergartenphase [Empirical Evaluation of the Pilot Project „Kindergarten of the Future - KiDZ". Results of the Kindergarten Years]. University of Bamberg Press.

*Sáez, L., Sidler Folsom, J., Al Otaiba, S., \& Schatschneider, C. (2012). Relations among student attention behaviors, teacher practices, and beginning word reading skill. Journal of Learning Disabilities, 45(5), 418432. https:// doi.org/10.1177/0022219411431243

*Sasser, T. R., Bierman, K. L., \& Heinrichs, B. (2015). Executive functioning and school adjustment: The mediational role of pre-kindergarten learning-related behaviors. Early Childhood Research Quarterly, 30, 70-79. https:// doi.org/10.1016/j.ecresq.2014.09.001

*Schmerold, K., Bock, A., Peterson, M., Leaf, B., Vennergrund, K., \& Pasnak, R. (2017). The relations between patterning, executive function, and mathematics. The Journal of Psychology, 151(2), 207-228. https://doi.org/10.1080/00223980.2016.1252708 
*Schmitt, S. A., Geldhof, J., Purpura, D., Duncan, R., \& McClelland, M. M. (2017). Examining the relations between executive function, math, and literacy during the transition to kindergarten: A multi-analytic approach. Journal of Educational Psychology, 109(8), 1120-1140. https://doi.org/10.1037/edu0000193

Schuchardt, K., \& Kuhn, J.-T. (2019). Komorbidität von Lernschwierigkeiten. Lernen und Lernstörungen, 8(1), 5-6. https://doi.org/10.1024/2235-0977/a000251

Schulze, S., \& Kuhl, J. (2019). Mathematical learning support and integrated working memory training. Lernen und Lernstörungen, 8(1), 47-59. https://doi.org/10.1024/2235-0977/a000229

*Schwarz, M., \& Shaul, S. (2018). Towards a better understanding of the link between executive functions, early literacy, and emergent mathematical abilities. Written Language \& Literacy, 21(2), 238-268. https://doi.org/10.1075/w11.00016.sch

Sedlmeier, P., \& Renkewitz, F. (2013). Forschungsmethoden und Statistik für Psychologen und Sozialwissenschaftler [Research Methods and Statistics for Psychologists and Social Scientists] (2nd ed.). Pearson.

*Segers, E., Kleemans, T., \& Verhoeven, L. (2015). Role of parent literacy and numeracy expectations and activities in predicting early numeracy skills. Mathematical Thinking and Learning, 17(2-3), 219-236. https://doi.org/10.1080/10986065.2015.1016819

*Sims, D. M., Purpura, D. J., \& Lonigan, C. J. (2016). The relation between inattentive and hyperactive/impulsive behaviors and early mathematics skills. Journal of Attention Disorders, 20(8), 704714. https:// doi.org/10.1177/1087054712464390

*Skwarchuk, S.-L., Sowinski, C., \& LeFevre, J.-A. (2014). Formal and informal home learning activities in relation to children's early numeracy and literacy skills: The development of a home numeracy model. Journal of Experimental Child Psychology, 121, 63-84. https:// doi.org/10.1016/j.jecp.2013.11.006

*Smith-Adcock, S., Leite, W., \& Amatea, E. (2019). A model of parenting risk and resilience, social-emotional readiness, and reading achievement in kindergarten children from low-income families model. Journal of Child and Family Studies, 28, 2826-2841. https:// doi.org/10.1007/s10826-019-01462-0

*Son, S.-H. C., Choi, J. Y., \& Kwon, K.-A. (2019). Reciprocal associations between inhibitory control and early academic skills: Evidence from a nationally representative sample of Head Start children. Early Education and Development, 30(4), 456-477. https://doi.org/10.1080/10409289.2019.1572382

*Soto-Calvo, E., Simmons, F. R., Willis, C., \& Adams, A.-M. (2015). Identifying the cognitive predictors of early counting and calculation skills: Evidence from a longitudinal study. Journal of Experimental Child Psychology, 140, 16-37. https://doi.org/10.1016/j.jecp.2015.06.011

*Stipek, D., \& Valentino, R. A. (2015). Early childhood memory and attention as predictors of academic growth trajectories. Journal of Educational Psychology, 107(3), 771-788. https://doi.org/10.1037/edu0000004

*Tindal, G., Irvin, S., \& Nese, J. F. (2015). Skills for children entering kindergarten. Educational Assessment, 20(4), 297-319. https://doi.org/10.1080/10627197.2015.1093929

*Trentacosta, C. J., \& Izard, C. E. (2007). Kindergarten children's emotion competence as a predictor of their academic competence in first grade. Emotion, 7(1), 77-88. https://doi.org/10.1037/1528-3542.7.1.77

*Vandenbroucke, L., Verschueren, K., Desoete, A., Aunio, P., Ghesquière, P., \& Baeyens, D. (2018). Crossing the bridge to elementary school: The development of children's working memory components in relation to teacher-student relationships and academic achievement. Early Childhood Research Quarterly, 42, 1-10. https:// doi.org/10.1016/j.ecresq.2017.08.004

Viljaranta, J., Lerkkanen, L.-K., Poikkeus, A.-M., Aunola, K., \& Nurmi, J.-E. (2009). Cross-lagged relations between task motivation and performance in arithmetic and literacy in kindergarten. Learning and Instruction, 19(4), 335-344. https:// doi.org/10.1016/j.learninstruc.2008.06.011

*Viterbori, P., Usai, C., Traverso, L., \& De Franchis, V. (2015). How preschool executive functioning predicts several aspects of math achievement in Grades 1 and 3: A longitudinal study. Journal of Experimental Child Psychology, 140, 38-55. https://doi.org/10.1016/j.jecp.2015.06.014

*Weiland, C., Ulvestad, K., Sachs, J., \& Yoshikawa, H. (2013). Associations between classroom quality and children's vocabulary and executive function skills in an urban public prekindergarten program. Early Childhood Research Quarterly, 28(2), 199-209. https:/ / doi.org/10.1016/j.ecresq.2012.12.002

*Welsh, J., Nix, R., Blair, C., Bierman, K., \& Nelson, K. (2010). The development of cognitive skills and gains in academic school readiness for children from low-income families. Journal of Educational Psychology, 102(1), 43-53. https:// doi.org/10.1037/a0016738 
*Willoughby, M., Blair, C., Wirth, R. J., \& Greenberg, M. (2012). The measurement of executive function at age 5: Psychometric properties and relationship to academic achievement. Psychological Assessment, 24, 226-236. https://doi.org/10.1037/a0025361

Wustmann Seiler, C., Müller, E., \& Simoni, H. (2017). The protective role of childcare quality for behavioral adjustment in 3- to 5-year-old children. Zeitschrift für Entwicklungspsychologie und Pädagogische Psychologie, 49, 1-10. https://doi.org/10.1026/0049-8637/a000162

*Zhang, X., \& Lin, D. (2018). Cognitive precursors of word reading versus arithmetic competencies in young Chinese children. Early Childhood Research Quarterly, 42, 55-65. https://doi.org/10.1016/j.ecresq.2017.08.006 